\title{
A INDISCIPLINA NA FORMAÇÃO INICIAL DE PROFESSORES/AS
}

\author{
INDISCIPLINE IN TEACHER'S INITIAL FORMATION
}

\section{Fernanda Martins Batista ${ }^{1}$ \\ Gislene Camargo ${ }^{2}$}

\begin{abstract}
RESUMO: O problema dessa pesquisa teve origem nas experiências vivenciadas no estágio não obrigatório, baseado nas dificuldades expressas pelos/as professores/as: Como o curso de pedagogia pode contribuir com os futuros/as professores/as a lidar com a indisciplina na escola? Desse modo foram elencados os objetivos: perceber o que é considerado indisciplina junto aos professores/as; relacionar a indisciplina às práticas pedagógicas; identificar as dificuldades dos/as professores/as recém-formados ao lidar com a indisciplina dos/as alunos/as. A pesquisa teve cunho qualitativo e ocorreu de forma bibliográfica, fundamentada por autores que discutem a Pedagogia e a indisciplina, e realizando um questionário no qual participaram sete docentes formadas em Pedagogia e que atuam nos anos iniciais do Ensino Fundamental. A partir da análise das pesquisadas e dos autores que referenciam teoricamente este trabalho, foi possível atingir os objetivos e concluir que as professoras pesquisadas atribuem a indisciplina à família, desconsiderando a organização escolar enquanto propulsora. As professoras demonstraram que no início da atuação foi mais difícil lidar com a indisciplina e que necessitam durante a formação de mais conhecimentos a esse respeito. As professoras sugeriram que durante a formação acadêmica, o curso de Pedagogia poderia contribuir mais, promovendo debates e pesquisas sobre o tema, apresentando os diferentes tipos de famílias que existem na sociedade e proporcionando a aproximação das mesmas as escolas. E sugeriram também aumentar a carga horária dos estágios obrigatórios, como forma de possibilitar aos/as acadêmicos/as uma maior experiência da realidade nas escolas e de relacionar melhor a teoria e a prática.
\end{abstract}

PALAVRAS CHAVE: Indisciplina. Professores. Formação. Pedagogia.

ABSTRACT: This research's problem was originated by experiences in the obligatory and non-obligatory traineeship, based on the difficulties that were manifested by teachers: How can the Pedagogy course contribute to the future teachers to deal with indiscipline at school? Thereby, the objectives were listed: to realize what is considered indiscipline by the teachers; to relate the indiscipline to the pedagogic practices; to identify the difficulties from the newgraduated teachers about the indiscipline with students. The research was qualitative and

\footnotetext{
${ }^{1}$ Graduanda em Pedagogia. Participante do Grupo de Pesquisa Políticas, Saberes e Práticas de Formação de Professores.

${ }^{2}$ Mestre em Educação. Coordenadora Adjunta do Curso de Pedagogia da UNESC. Coordenadora do Pibid Subprojeto Educação Infantil e Alfabetização e Letramento. Líder do Grupo de Pesquisa Políticas, Saberes e Práticas de Formação de Porfessores.

Saberes Pedagógicos, Criciúma, v. 1, nº1, janeiro/junho 2017.- Curso de Pedagogia- UNESC
} 
Revista do Curso de Graduação de Pedagogia - Unesc

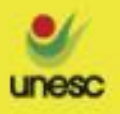

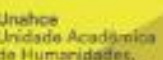

ediunesc

bibliographic, based on authors who discuss Pedagogy and indiscipline, and accomplished by a questionnaire that was answered by seven feminine graduated teachers who work in the first years of the Elementary School. From this analysis about the researched people and the authors who reference theoretically this study, it was possible to reach the objectives and to conclude that the researched teachers attribute the indiscipline to the students' families, disregarding the school organization as a promoter. The teachers demonstrated that in the beggining of the career it was harder to deal with the indiscipline and that they need, during the training, more knowledge about this issue. The teachers suggested that, during the academic formation, the Pedagogy course could contribute more, promoting debates and researches about the theme, presenting the different kinds of family in the society and providing the access of these families to the school. They also suggested to increase the quantity of the obligatory traineeship hours, as a way to enable the future teachers a better experience about the school reality and to build a better connection between theory and practice.

KEYWORDS: Indiscipline. Teachers. Formation. Pedagogy.

\section{INTRODUÇÃO}

O tema "A Indisciplina na Formação Inicial de Professores/as" surgiu a partir do período em que realizei os estágios, tanto o não obrigatório quanto o obrigatório. Durante este período me deparei com a indisciplina dos/as alunos/as, principalmente nos $5^{\circ}$ anos, e com os/as professores/as mal preparados para lidar com tal questão, bem como a equipe diretiva. Percebi que a "solução" para os/as professores/as era encaminhar para a direção, onde conversavam com os/as alunos/as e não adiantando, os pais eram chamados na escola. Ainda assim, o problema continuava, e dependendo da situação, surgia a questão de expulsão. Nesse sentido configurou-se o problema da pesquisa: Como o curso de Pedagogia pode contribuir com os futuros/as professores/as a lidar com a indisciplina na escola?

A indisciplina nas escolas parece se agravar com o passar do tempo, cada vez mais os/as alunos/as se mostram rebeldes e violentos, faltando educação para com os/as professores/as, colegas e funcionários das escolas. Essas atitudes interferem diretamente no convívio escolar e no processo de ensino-aprendizagem da turma, sendo que o/a professor/a precisa interromper a aula para lidar com os/as alunos/as em questão que não se comportam de forma adequada e dispersam a atenção de toda a turma. 
Revista do Curso de Graduação de Pedagogia - Unesc

Não compreendemos se o "problema" desses/as alunos/as é uma questão de estrutura familiar, dificuldade na aprendizagem ou até mesmo com o próprio/a professor/a da sala que não sabe impor limites e ter autoridade com a turma, talvez falte um aprofundamento deste assunto tanto nos Cursos de Pedagogia quanto nas próprias instituições de ensino, formações continuadas e afins.

Este trabalho tem por objetivo geral compreender o papel da formação acadêmica na capacitação dos/as professores/as para lidarem com a indisciplina nas escolas, e por objetivos específicos buscar: Perceber o que é considerado indisciplina junto aos professores/as; Relacionar a indisciplina às práticas pedagógicas; Identificar as dificuldades dos/as professores/as recém-formados ao lidar com a indisciplina dos/as alunos/as.

Ao pesquisar sobre o tema em questão me deparei com a falta de material que aborde a indisciplina de um modo mais aprofundado, além de ter encontrado poucas referências atuais. Este é mais um ponto a ser discutido, sendo a indisciplina um dos problemas enfrentados pelos/as professores/as nas escolas, ainda existem pouquíssimos autores que discutam esta problemática importante para a melhoria da qualidade da educação.

Este trabalho se encontra na linha de pesquisa: Políticas Educacionais e Formação dos Profissionais da Educação. A pesquisa foi fundamentada por livros relacionados com a Pedagogia e a indisciplina, sendo realizada também uma pesquisa campo com sete docentes que estejam atuando com o Ensino Fundamental, formados/as em Pedagogia.

\section{ASPECTOS DA TRAJETÓRIA DA PEDAgOGia E SUAS RELAÇÕES COM A INDISCIPLINA}

Esta seção fará uma breve abordagem sobre a história da Pedagogia no Brasil desde a chegada dos jesuítas ao território, relacionado a disciplina que era exigida pelos educadores daquela época, até o curso de Pedagogia nos dias de hoje e a dificuldade dos professores em lidar com a indisciplina dos alunos.

A Pedagogia no Brasil teve seus primeiros indícios com a chegada dos jesuítas, no século XVI, que vieram ao território com a intenção de catequizar os índios que aqui viviam. Segundo Aranha (2006) os religiosos foram enviados para o trabalho missionário e 
Revista do Curso de Graduação de Pedagogia - Unesc

pedagógico, com a intenção de converter os nativos e impedir que os colonos se desvirtuassem da fé católica. Percebe-se que a finalidade dos missionários jesuítas era disciplinar os índios com os seus costumes e sua fé no catolicismo, tornando-os pessoas civilizadas e educadas.

Para disciplinar os índios, tanto com a educação moral, como com a comportamental, os jesuítas utilizavam do castigo. Era através do medo que conseguiam fazer com que os índios se comportassem conforme as normas estabelecidas (FERREIRA, 2004). Era dessa forma, através de castigos e punições, que o ensino era ofertado, impondo o medo para alcançar o objetivo desejado.

O objetivo das missões criadas pelos jesuítas foi alcançado, de modo que os índios aprenderam a ler, escrever e se especializar em artes e ofícios mecânicos, além de serem convertidos religiosamente (ARANHA, 2006). Foi durante esse período, com a chegada dos colonizadores e jesuítas, que teve início a educação em nosso país, com uma pedagogia conservadora, onde a cultura e a fé católica dos outros povos foram implantadas com os índios, através do disciplinamento.

Segundo Saviani (2008) os jesuítas ampliaram sua atuação ao vasto território conquistado pelos portugueses, fazendo com que o ensino organizado por eles fosse considerado um sistema educacional. Pode-se dizer, portanto, que o primeiro sistema educacional no Brasil teve início no século XVI, com a organização das missões criadas pelos jesuítas.

Passado o período da ação missionária, já em 1772, com a reforma pombalina no Brasil, foi implantado o ensino público oficial, onde a Coroa nomeou professores, criou planos de estudos e modificou o curso de humanidades, que era típico do ensino jesuítico, para o ensino de aulas régias de disciplinas isoladas (ARANHA, 2006). Nesse período, devido as grandes mudanças no sistema, a autora afirma que houve um retrocesso no ensino brasileiro, já que o ensino jesuítico foi substituído e a proposta da reforma pombalina para um novo ensino não foi introduzida de imediato, causando um rompimento no sistema educacional, que deixou de existir por um tempo.

As escolas só começaram a surgir com a chegada da família real ao Brasil. De acordo com Aranha (2006), assim que D. João VI chegou, em 1808, foram criadas as 
Revista do Curso de Graduação de Pedagogia - Unesc

primeiras escolas de ensino superior, com a finalidade de formar oficiais do exército e da marinha, engenheiros militares e médicos. Entende-se que estes profissionais, desenvolviam aspectos de disciplina nas suas formações profissionais, sendo que os mesmos iriam servir a família real e precisariam estar bem preparados para tal função.

Compreende-se que até a chegada da família real a preocupação maior em relação a educação, era em disciplinar as pessoas, de modo que fossem civilizadas e educadas para viver em sociedade. Após a vinda da realeza e de muitos nobres que os acompanharam até o Brasil, a preocupação passou a ser com os cursos superiores, com a formação de médicos, advogados e militares.

O primeiro nível da educação era o ensino primário, que não era exigida sua conclusão para o acesso aos próximos níveis, sendo assim, a elite educava seus filhos em casa, com preceptores (ARANHA, 2006). Ainda segundo a autora Aranha (2006, p. 223), “[...]para os demais segmentos sociais, restava a oferta de poucas escolas cuja atividade se restringia à instrução elementar: ler, escrever e contar. " Entende-se que a educação ainda era bem precária naquela época, com pouca demanda e poucas escolas, sendo que os filhos da elite eram educados e disciplinados em casa, ou em pequenos grupos, e os filhos dos plebeus recebiam o básico do ensino com professores que muitas vezes não possuíam formação alguma.

De acordo com Saviani (2008), o método de ensino adotado naquela época era o "ensino mútuo", os alunos mais adiantados eram promovidos a auxiliares dos professores nas salas mais cheias, onde existiam regras e uma disciplina rigorosa. Observa-se que ainda existiam os castigos para disciplinar os alunos, além de que era priorizado a memorização, assim como no método tradicional. $\mathrm{O}$ autor descreve que durante as aulas não era permitido a conversa, sendo esta considerada uma indisciplina, pois não era possível falar e aprender ao mesmo tempo.

A formação de professores era algo precário naquele tempo, pois a sociedade não priorizava a educação primária e eram aceitos professores despreparados, seguindo um pressuposto de que não era necessário nenhum método pedagógico específico (ARANHA, 2006). Sendo a educação primária algo não relevante na sociedade que se tinha naquela época 
Revista do Curso de Graduação de Pedagogia - Unesc

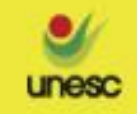

Unahos

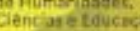

a formação de professores para tal função era desprezada, pois a sociedade ainda não possuía consciência da importância da educação na vida das crianças e jovens.

Saviani (2008) ressalta que naquela época a ideia pedagógica era de que a formação de professores acontecia na prática. Por esse motivo pessoas despreparadas eram contratadas para assumir as aulas, a profissão não era relevante a ponto de se preocuparem com uma formação qualificada, qualquer um poderia assumir as aulas e com o tempo iria adquirir experiência.

Segundo Aranha (2006) as escolas normais eram oferecidas apenas para rapazes, somente após trinta anos de fundação a primeira escola de São Paulo passou a oferecer formação para mulheres, que com o tempo predominaram na profissão do magistério. A autora ainda afirma que esta era uma atividade aceita na sociedade já que a mulher estava ligada à maternidade. Entende-se a relação da mulher, como figura materna, à profissão do magistério, pois entendia-se que a mulher já nascia com o dom para lidar com crianças, cuidar e ensinar, além de ser algo bem visto na sociedade daquela época.

A partir de 1860 a sociedade despertava um interesse maior pela educação, foram adotadas medidas para melhorar o ensino, e a formação dos professores ganhou reconhecimento (ARANHA, 2006). Percebe-se que no final do século XIX já começam as mudanças positivas em relação a educação, a sociedade começa a sentir a necessidade de uma educação de qualidade, tanto para as crianças, quanto na formação dos/as professores/as.

Segundo Villela (2000) entre 1868 a 1876 as mudanças foram bem significativas, as Escolas Normais começaram a rejeitar os castigos corporais como forma de disciplinar, e o método adotado passou de mútuo para lição de coisas, onde era modificado o fazer na sala de aula, necessitando de novas ferramentas didáticas e uma nova organização para as dinâmicas escolares. Neste período os materiais didáticos e as dinâmicas nas aulas ganharam espaço e variedade dentro das escolas, enriquecendo o ensino.

O método lição de coisas, também chamado de método intuitivo, de acordo com Aranha (2006) priorizava a educação pela sensibilidade, por meio das cores, formas, sons, luzes etc. Ao contrário do método tradicional, onde o ensino era somente discursivo, o método lição de coisas oportunizava a expressividade dos alunos, de modo que pudessem participar mais das aulas. 
Revista do Curso de Graduação de Pedagogia - Unesc

Porém, essa educação mais qualificada não durou muito tempo, de acordo com Villela (2000) em 1849 o presidente Couto Ferraz emitiu um Regulamento que rebaixava o ensino primário e também o nível de formação dos/as professores/as, que para continuar lecionando teriam que seguir várias regras, dentre elas frequentar a missa aos domingos e adotar meios de punição para os alunos. A intenção do presidente com as escolas não estava mais em educar, mas sim em moralizar e disciplinar, tanto os professores como os alunos.

Percebe-se que a educação passou por diferentes fases durante o século XIX, prevalecendo a educação rígida, através de castigos e punições. Definir um modelo de ensino de qualidade não era prioridade para alguns governantes, que, sob grande influência no Estado, dificultavam a luta contra o que era imposto.

Segundo Aranha (2006) no final do século XIX foi criado um modelo de escola seriada, que só ganhou força no início do século XX, era uma escola com regras, métodos e uma estrutura adequada, que demonstrava o empenho do governo por um bom ensino público. Entende-se que nessa época começaram as mudanças positivas em relação a educação pública, o governo passa a se importar com o ensino e investir em melhorias nas escolas.

Saviani (2008) relata sobre o ensino público único, criado pelo Estado, para ofertar uma educação igual para todos, onde não haverá disputa de religiões, todos terão acesso gratuitamente, o ensino se estenderá até os 18 anos, obrigatoriamente, e onde não será feita divisão por sexo entre os alunos. A partir disso percebe-se que a educação pública ganhou força, as escolas já tomam a forma que possuem hoje em dia, com normas, obrigatoriedade, sem distinção de sexo ou religiões.

Apesar de todas essas mudanças positivas para a educação, as escolas enfrentavam sérios problemas relacionados a disciplina dos alunos, segundo Nunes (2000) essa indisciplina ocorria na questão dos bons costumes, os alunos se comportavam de maneira inadequada, com insinuações, masturbação em lugares públicos e a ingestão de bebidas alcoólicas. Entende-se que esse comportamento era uma forma de se rebelar contra as novas normas, como a obrigatoriedade de frequentar a escola, algo novo para eles, pois muitos jovens passaram anos sem conhecer uma escola, e de repente se viram obrigados a comparecer nas aulas e seguir normas que até então não existiam. 
Revista do Curso de Graduação de Pedagogia - Unesc

Percebe-se que a partir do século XX a indisciplina começa a se tornar presente na escola, o que não acontecia explicitamente nos séculos passados devido aos castigos e punições dos educadores pelos maus comportamentos dos alunos, algo que já não era mais permitido nas escolas da época.

No século XX também aconteceu a criação do curso de Pedagogia que, segundo Silva (1999), foi criado em 1939 pelo Decreto-lei $\mathrm{n}^{\circ} 1190$ de 4 de abril, o curso era dividido em bacharel e licenciatura, sendo que eram 3 anos de curso para o diploma de bacharel e realizando 1 ano do curso de Didática conquistava-se o diploma de licenciatura em Pedagogia. Compreende-se que a formação de professores/as começou a ser mais valorizada e reconhecida a partir da criação do curso.

Segundo Xavier (2002) a partir dos anos 80 a formação de professores/as para os anos iniciais do ensino básico passou a ser priorizada, buscava-se formar professores/as engajados no processo de democratização da escola, que estivessem dispostos a elaborar projetos que garantissem a permanência dos/as alunos/as que eram excluídos do sistema escolar. Nessa época, ainda segundo a autora acima, a questão disciplinar começou a ser estudada, de modo que auxiliasse nas novas práticas pedagógicas que estavam sendo defendidas.

\subsection{Conceituando indisciplina}

A indisciplina, sendo um dos maiores desafios encontrados pelos/as professores/as na sala de aula atual, é uma questão que gera muitas discussões nas escolas e deve ser estudada e aprofundada entre os educadores/as.

Para melhor abordar sobre o tema, veremos qual o significado das palavras disciplina e indisciplina segundo o dicionário Michaelis (2010, p. 303),

Disciplina 1 Ensino, instrução e educação. 2 Relação de subordinação do aluno para com o professor; observância de preceitos ou ordens escolares: Disciplina escolar. 3 Observância estrita de normas de uma organização: Disciplina militar. 4 Ramos do conhecimento científico, artístico etc., que se professam em cada cadeira de um estabelecimento escolar; matéria. 5 Obediência à autoridade. 6 Procedimento correto. 
Revista do Curso de Graduação de Pedagogia - Unesc

No que diz respeito à escola, o dicionário citado, define a disciplina como ser obediente com o/a professor/a, respeitar as regras impostas e comportar-se corretamente, ser subordinado, visando a boa convivência no ambiente escolar.

Já o termo indisciplina, ainda de acordo com o dicionário Michaelis (2010, p. 471), refere-se a "1 Falta de disciplina. 2 Ato ou dito contrário à disciplina. 3 Desobediência, desordem, rebelião."

A indisciplina é a falta dessa obediência e respeito, podendo se manifestar de várias formas no cotidiano das escolas, desde o/a aluno/a que desrespeita professores/as, funcionários/as e colegas, até o/a aluno/a que agride moral e fisicamente as pessoas do convívio escolar. Dados esses conceitos, fica a pergunta: O que causa a indisciplina?

São muitas as controvérsias para responder esta pergunta, há quem diga que é devido a família, que não impõe limites em casa e acredita que a responsabilidade de educar o/a filho/a é da escola, outros que culpam a escola ou o próprio/a professor/a, que não é competente ou não tem autoridade com o/a aluno/a, mas também existe a possibilidade de ser algo da criança, alguma dificuldade que ainda não foi identificada e por isso as atitudes indisciplinares, ou algo que a esteja incomodando.

Segundo Rego (1996) as justificativas para a indisciplina são cheias de meiasverdades, de explicações sem consistência, as pessoas vão empurrando a culpa para o próximo e ninguém é responsabilizado. Poucos estão realmente preocupados em encontrar uma solução para reverter esse quadro nas escolas, pois é mais fácil reclamar do que se aprofundar no assunto e tentar melhorar a situação.

A indisciplina se manifesta de várias formas dentro da escola, de acordo com os estudos de Fortuna (2002) a grande queixa dos/as professores/as está relacionada a falta de atenção, ao desinteresse dos/as alunos/as que acabam tumultuando as aulas e gerando dificuldade na aprendizagem da turma inteira. Além de, em alguns casos, ocasionar a violência nas escolas, que acontecem na forma verbal, física e também na depredação dos materiais da escola.

É nesse momento que se percebe um despreparo dos/as professores/as e equipe diretiva sobre como agir com esses/as alunos/as, como diagnosticar a causa do desinteresse e 
Revista do Curso de Graduação de Pedagogia - Unesc

violência para, a partir deste diagnóstico, encontrar uma forma de intervenção adequada para promover um bom convívio e um aprendizado de qualidade.

Segundo Vieira e Veronese (2006) a disciplina escolar é um conjunto de regras que o aluno deve seguir, relacionadas ao cumprimento de seus deveres e o respeito aos limites necessários para um bom convívio escolar. Para que isto seja possível os autores discorrem sobre a criação de normas disciplinares, juntamente com os alunos, pois desta forma a disciplina irá favorecer a relação professor-aluno, já que ambos determinarão as regras para a boa convivência e se comprometerão em cumpri-las.

As normas disciplinares são boas aliadas dos/as professores/as para manter a disciplina dos/as alunos/as em sala de aula, já que quando participam da construção das normas eles/as se sentem valorizados/as e respeitados/as, pois não foi algo imposto que deveria ser cumprido, e sim um combinado entre professor/a e aluno/a, onde ambos podem expressar suas opiniões e chegar a um consenso sobre a melhor forma de manter uma boa relação em sala de aula e um bom desempenho pedagógico.

Ao construir as normas disciplinares com os/as alunos/as, os/as professores/as não podem esquecer do que consta no artigo 18 do Estatuto da Criança e do Adolescente, onde diz que devem zelar pela dignidade da criança e do adolescente e que não podem expor os/as alunos/as a situações desumanas, violentas, aterrorizantes, vexatórias ou de constrangimento (VIEIRA; VERONESE, 2006). Não importa quão séria foi a atitude indisciplinar do/a aluno/a, o/a professor/a jamais pode agir de maneira inadequada, deve sempre prezar pela ética no trabalho e agir de forma pedagógica para que o/ aluno/a entenda que sua atitude não foi adequada e que deverá repensar sua postura em sala de aula.

Para lidar com os atos de indisciplina os/as professores/as podem se espelhar nos artigos 101 e 112 do Estatuto da Criança e do Adolescente que falam sobre as medidas protetoras e socioeducativas que estão assim determinadas:

\footnotetext{
Art. 101. Verificada qualquer das hipóteses previstas no art. 98, a autoridade competente poderá determinar, dentre outras, as seguintes medidas:

I-encaminhamento aos pais ou responsáveis, mediante termo de responsabilidade; II-orientação, apoio e acompanhamento temporários;

III- matrícula e frequência obrigatórias em estabelecimento oficial de ensino fundamental;

IV-inclusão em programa comunitário ou oficial de auxílio a família, à criança e ao adolescente;
}

Saberes Pedagógicos, Criciúma, v. 1, nº 1, janeiro/junho 2017.- Curso de Pedagogia- UNESC 
Revista do Curso de Graduação de Pedagogia - Unesc

V-requisição de tratamento médico, psicológico ou psiquiátrico, em regime hospitalar ou ambulatorial;

VI-inclusão em programa oficial ou comunitário de auxílio, orientação e tratamento a alcoólatras e toxicômanos;

VII-abrigo em entidade;

VIII-colocação em família substituta. (BRASIL, 2008, p.33)

Art. 112.Verificada a prática de ato infracional, a autoridade competente poderá aplicar ao adolescente as seguintes medidas:

I- advertência;

II- obrigação de reparar o dano;

III- prestação de serviços à comunidade;

IV- liberdade assistida;

V- inserção em regime de semiliberdade;

VI- internação em estabelecimento educacional;

VII- qualquer uma das previstas no art. 101, I a VI. (BRASIL, 2008, p.36)

A partir do despreparo dos/as professores/as, quando acontece um ato de indisciplina por parte dos/as alunos/as e o/a professor/a, ou até mesmo a equipe diretiva da escola, não estão preparados para lidar com o caso, vale dar uma olhada no Estatuto para tomar a providência de forma correta, sem ferir os direitos que estão garantidos na lei. Existem muitas formas de corrigir a indisciplina dos/as alunos/as sem partir para medidas extremas e descabidas, como eram feitas nos séculos passados, os/as professores/as devem procurar meios pedagógicos para lidar com esse tipo de situação.

Vieira e Veronese (2006) propõem que nestes casos a escola procure resolver o problema dentro do seu ambiente, de forma que reveja suas práticas, redimensione a relação professor-aluno e, em último caso, aplique a medida repressiva prevista no regime disciplinar da escola, sendo que esta medida não pode ocasionar na expulsão do/a aluno/a, pois o mesmo tem o direito à educação garantido, e deve ocorrer de forma pedagógica, visando a formação educacional do/a aluno/a.

Essa seria a forma correta de lidar com a indisciplina, mas o que percebemos é o despreparo de toda a equipe escolar, sendo que muitas vezes o/a aluno/a acaba sendo expulso da escola, pois não souberam reverter o problema aplicando as medidas corretas e pedagógicas.

\section{METODOLOGIA, APRESENTAÇÃO E ANÁLISE DE DADOS}


Revista do Curso de Graduação de Pedagogia - Unesc

O presente trabalho de pesquisa aborda a questão da discussão da indisciplina na formação de professores/as do Curso de Pedagogia. O objetivo da pesquisa seguiu de forma descritiva, onde foram descritas as características de determinado grupo, utilizando a coleta de dados, e levantamento de opiniões (GIL, 1996).

A pesquisa exploratória ocorreu de forma bibliográfica, relatando as características da situação investigada, detalhando-as e analisando-as. Segundo Gil (1996) as pesquisas bibliográficas são elaboradas a partir de livros e artigos já publicados, considerando, dessa forma, a opinião de diferentes autores acerca do tema estabelecido.

O problema da pesquisa segue uma abordagem qualitativa, pois foi desenvolvida de forma ampla e direcionada para que se encontrasse a resposta do problema: Como a formação acadêmica do Curso de Pedagogia pode contribuir com os/as futuros/as professores/as a lidar/enfrentar com a indisciplina nas escolas?

Os sujeitos da pesquisa foram sete professoras $^{3}$, que atuam na AMREC da cidade de Criciúma na área do Ensino Fundamental, de $1^{\circ}$ a $5^{\circ}$ ano. Para coleta de dados foi utilizado como instrumento de pesquisa o questionário, onde os/as professores/as responderam a seis questões sobre o tema indisciplina, relacionadas à sua formação acadêmica e atuação na sala de aula. Os questionários foram entregues no dia $1^{\circ}$ de setembro, com prazo de uma semana para a entrega e com o termo de consentimento assinado. No dia combinado para a entrega do questionário a maioria das professoras havia esquecido, sendo que só consegui recolher o de todas após uma semana do prazo combinado.

A análise das respostas foi dividida em duas categorias: A indisciplina sobre o olhar pedagógico, onde foram analisadas as questões sobre o que as professoras consideram como indisciplina e quais atitudes são tomadas pela escola. E os reflexos da formação do/a professor/a nos encaminhamentos sobre a indisciplina, onde foram analisadas questões sobre as dificuldades no início da docência, sobre suas formações acadêmicas, se foi discutido sobre indisciplina, e de qual forma o curso de Pedagogia poderia contribuir com os/as futuros/as professores/as a lidar com essa temática.

\subsection{A indisciplina sobre o olhar pedagógico}

3 Observou-se que o quadro de docentes, formados em Pedagogia, que atuam nos anos inicias é predominantemente feminino.

Saberes Pedagógicos, Criciúma, v. 1, nº1, janeiro/junho 2017.- Curso de Pedagogia- UNESC 
Quando questionadas sobre o que consideravam indisciplina, as sete professoras responderam que se refere ao não cumprimento de regras, mal comportamento, falta de limites e desrespeito, essas são as maiores queixas e vão contra a disciplina escolar que, segundo Vieira e Veronese (2006), é um conjunto de regras que devem ser respeitadas para que se consiga um bom desenvolvimento no processo de ensino-aprendizagem.

A professora A estendeu sua resposta, além de citar a falta de regras e limites, ela menciona que “[...] o perfil familiar vem mudando consideravelmente nos últimos anos. A tarefa de 'EDUCAR' está sendo delegada à escola, recebemos alunos cujo primeiro não será ouvido na escola, tal realidade está ofuscando nossa função maior que é a de escolarização". Essa fala reforça o que é abordado nos estudos de Fortuna (2002) que a escola está tendo que assumir o papel dos pais na educação moral dos filhos, o que parece estar sobrecarregando os/as professores/as que estão assumindo esse papel que cabe à família. Cabe ressaltar que cada família tem seus hábitos, suas histórias e que o que é errado para uma família, para a outra não causa estranhamento. Destacando também que há regras diferentes na escola e em casa.

Ainda segundo Fortuna (2002) a indisciplina é mais do que só o descumprimento de regras, ela pode representar a maneira com a qual os/as alunos/as reagem as normas impostas pela escola, já que muitas vezes essas normas não são construídas com a turma, e sim, apenas apresentadas depois de pronta, logo, um/a aluno/a que não concorde ou questione tal norma é considerado indisciplinado. Além de que para determinadas crianças, receber um não ou ter que respeitar normas, pode causar reações adversas.

Através da fala da autora acima citada, percebe-se que nem sempre os casos de indisciplina acontecem por influência do meio externo em que a criança se encontra inserida, como a falta de limites ou educação por parte da família, mas sim por situações em que o/a aluno/a se depara dentro da escola, uma má relação com o/a professor/a, o abuso de autoridade, falta do diálogo, fazendo com que ele se sinta reprimido, sem poder manifestar suas opiniões, encontrando nas atitudes de "rebeldia" uma forma de se expressar. O diálogo é uma das maneiras de evitar conflitos, o/a aluno/a precisa ser ouvido, pode por meio da conversa expressar o que o deixa "rebelde". 
Revista do Curso de Graduação de Pedagogia - Unesc

A partir das respostas das pesquisadas, observa-se que elas não consideram como causa da indisciplina fatores que acontecem dentro da escola, ou até mesmo suas próprias condutas, deixando claro que, na visão delas, a indisciplina é a falta de limite, a má educação que não foi dada em casa, não levando em consideração o que Fortuna (2002) defende quando relata que o problema pode estar na organização da escola. Desse modo, as pesquisadas veem que a indisciplina vem de casa ou de fora da escola.

Uma pergunta indagava sobre o que o Projeto Político Pedagógico da escola diz sobre a indisciplina e quais atitudes são adotadas. A professora E relatou que a indisciplina é abordada de modo geral, sem distinção de idade, sendo que as atitudes adotadas são registrar a ocorrência do/a aluno/a, conversar com a coordenação, chamar os responsáveis e, quando necessário, suspender o aluno. A professora B relata que a escola "procura meios para minimizar a indisciplina, acha essencial a relação do aluno, professor, escola e pais", outras duas ainda relataram que existem orientações para os/as alunos/as, discutindo as normas da escola, e quando o/a aluno/a descumpre alguma norma é advertido, e se reincidente, recebe suspensão.

As professoras C, D e F argumentaram que o PPP da escola não aborda especificamente sobre a indisciplina, a questão é abordada no regimento escolar, mas que as atitudes adotadas para os casos são o diálogo e a aproximação da família com a escola.

De acordo com Vieira e Veronese (2006) em casos de indisciplina a escola deve agir de forma pedagógica, revendo suas práticas ou melhorando a relação professor-aluno, sendo que as medidas adotadas para os casos devem estar previstas no regimento disciplinar da escola, e o/a aluno/a não pode ser expulso ou suspenso, pois o mesmo tem o direito a educação escolar garantido no Estatuto da Criança e do Adolescente.

Com base no que Vieira e Veronese (2006) defendem e nas falas das pesquisadas, observa-se que algumas escolas precisam rever seus regulamentos e normas, visto que entre as atitudes adotadas para os casos de indisciplina a suspensão do/a aluno/a ainda é uma opção, mesmo indo contra o Estatuto. A escola deve buscar medidas pedagógicas para reverter a situação, é preciso que a equipe escolar, unida, repense o que está errado, onde precisam mudar, de que forma podem ajudar esses/as alunos/as, seja por meio de palestras sobre o tema, seja revendo suas práticas ou que os/as alunos/as passem por acompanhamento 
Revista do Curso de Graduação de Pedagogia - Unesc

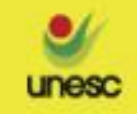

psicopedagógico ou psicológico, quando necessário. Enfim, são inúmeras as formas para encontrar a raiz do problema e buscar soluções para contorná-lo, é preciso firmeza para lidar com as situações, mas é importante que os/as alunos/as se sintam seguros, que tenham abertura para falar, cientes de que a escola pode auxiliar e não somente repreender.

\subsection{Os reflexos da formação do professor nos encaminhamentos sobre a indisciplina}

Ao serem questionadas sobre as maiores dificuldades encontradas no início da atuação como professoras, elas apresentaram respostas diversas. As professoras A, E e F relataram que suas maiores dificuldades foram relacionadas ao comportamento dos/as alunos/as, sobre de que forma conduzir a turma, como lidar com o enfrentamento dos/as alunos/as.

Pensando nisso, de acordo com os autores citados na fundamentação teórica, essa é uma questão que precisa ser trabalhada com os/as professores/as durante a formação, possibilitando que eles/as saiam do curso cientes das situações com as quais podem se deparar e saber a melhor forma de agir. Em consonância a isso, Rego (1996) argumenta que os/as professores/as precisam aprender a se adequar as necessidades e possibilidades dos/as alunos/as, ensinando e possibilitando que eles aprendam e construam, juntos, os valores a serem internalizados e praticados no convívio social. Desse modo, é possível refletir que cada escola tem suas regras, seus regimentos, sua identidade e que cada turma tem suas especificidades. Não há manual para tratar da indisciplina, porém, há referenciais teóricos que sustentam as práticas pedagógicas.

Nesse sentido, duas professoras relataram que a maior dificuldade foi relacionar a teoria estudada durante a graduação e a prática na realidade escolar, entende-se que essa é uma dificuldade que pode ser superada a partir das vivências relacionadas ao processo de ensino-aprendizagem. Através da fala das professoras percebe-se que com o tempo o/a professor/a irá conhecer as necessidades da turma e saberá como trabalhar, assim como Vieira e Veronese (2006) abordam em seus estudos, que a realidade é o ponto inicial para o processo de ensino e aprendizagem no começo da carreira dos/as professores/as, é a partir da realidade em que se encontra que ele/a irá compreender de qual forma terá que trabalhar para atingir 


\section{SABERES PEDAGÓGICOS}

Revista do Curso de Graduação de Pedagogia - Unesc

\section{seus objetivos e superar suas dificuldades.}

Quando questionadas sobre como lidaram com essas dificuldades, três das sete professoras relataram que foi através do diálogo com professores/as mais experientes, equipe pedagógica e participação em cursos e seminários que conseguiram superá-las. Outras responderam que foi com a convivência com os/as alunos/as, conhecendo a realidade da comunidade escolar e fazendo adaptações para suprir as necessidades e concretizar a prática, as professoras D e E ainda mencionaram a importância do vínculo afetivo para conquistar a confiança da turma, esse é um aspecto importante a se considerar para tornar o processo de ensino-aprendizagem prazeroso para ambos, assim como afirma Xavier (2002) que a figura da professora comprometida é defendida durante sua formação, aquela que cativa os/as alunos/as propondo atividades significativas, que possibilita a troca de opiniões, os trabalhos em equipes, que ensina com prazer, de modo que os/as alunos/as também sintam prazer na aprendizagem.

O que se percebe em comum nas respostas das professoras é que as dificuldades foram superadas com a prática, no dia a dia com a turma e na troca de experiências com a equipe escolar, o que mostra que durante suas formações a teoria e a prática não foram bem relacionadas, de modo que o como agir na sala de aula ficou de lado, e foi somente vivenciando a realidade de atuar em uma sala de aula que as professoras compreenderam de que forma precisavam prosseguir e quais atitudes tomar mediante as situações que surgiam. Essas respostas remetem ao ensino que se tinha no século XVIII do qual Saviani (2008) aborda em seus estudos, sobre a fraca formação de professores da época, onde as escolas normais foram substituídas por professores adjuntos, cuja ideia pedagógica era a de uma formação que se consolidasse na prática.

Percebe-se que apesar das diversas mudanças que ocorreram, ainda há um distanciamento entre a teoria e a prática. Alguns programas do governo, como o Programa Institucional de Bolsa de Iniciação à Docência, surgiram para amenizar essa distância, sendo que os/as acadêmicos/as são inseridos na escola com supervisão de professores e coordenados por um professor da universidade. Porém, nem todos/as acadêmicos/as são bolsistas, e precisam estabelecer essas relações nos estágios obrigatórios e não obrigatórios.

Uma das questões indagava se durante a formação acadêmica houve um momento 
Revista do Curso de Graduação de Pedagogia - Unesc

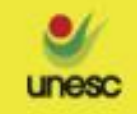

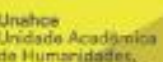

benciare toviciciac

ediunesc

de discussão e preparo para lidar com a indisciplina na sala de aula, seis das sete professoras responderam que havia discussões acerca do tema, mas não um preparo para lidar com esse problema, existiam diálogos, trocas de experiências, dinâmicas e estudos de textos, mas como relata a professora A "[...] nada tão concreto como a realidade que encontramos ao ingressarmos na heterogeneidade de uma sala de aula". Percebe-se que nesse aspecto predomina a teoria na discussão sobre o tema, de forma que a prática ocorre de forma superficial, não mostrando a realidade que se encontra nas escolas, o que "assusta" os/as professores/as iniciantes.

Quando foram questionadas sobre de que forma o Curso de Pedagogia pode contribuir para preparar os/as professores/as a lidar com a indisciplina dos alunos, cinco das sete professoras sugeriram que através de debates, palestras e pesquisas para encontrar estratégias para sanar essas dificuldades, três delas ainda sugerem que sejam criados mecanismos para aproximar a família e a comunidade da escola, que sejam apresentados os diferentes tipos de famílias que existem na sociedade, pois suas características acabam refletindo no comportamento dos/as alunos/as. A professora E também sugeriu que fosse criada uma disciplina específica para o tema, já a professora A acredita que aumentando a carga horária dos estágios os/as futuros/as professores/as poderiam conhecer melhor a realidade com a qual irão trabalhar.

De acordo com a análise das questões, as professoras propuseram diversas sugestões para melhorar a formação dos/as acadêmicos/as do Curso de Pedagogia, auxiliando a prepará-los/as para a realidade que encontrarão nas escolas, estudando os diferentes tipos de situações que podem encontrar e pensando juntos em soluções mais adequadas para cada ocasião.

A sugestão do aumento da carga horária dos estágios é uma possibilidade que pode enriquecer a formação dos/as professores/as, visto que com mais tempo atuando seria possível colocar em prática a teoria discutida durante o curso, além de proporcionar uma experiência concreta de como é a rotina em uma sala de aula, dos imprevistos que podem acontecer e de como proceder em determinadas situações. Outro ponto positivo seria que devido as diferentes realidades que cada acadêmico/a do curso encontraria nesse período, a socialização e troca de experiências sobre o estágio seria valiosa e acrescentaria muito na 
preparação dos/as futuros/as professores/as.

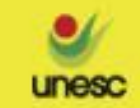

Com base nos estudos dos autores defendidos no referencial, observa-se que a Pedagogia passou por várias mudanças desde o início da formação de professores e ao analisar as respostas das pesquisadas, percebe-se que ainda existem pontos que podem ser aprimorados no curso, de modo que possibilite uma melhor experiência com a realidade, e também uma maior articulação da teoria e da prática. Aranha (2006) aponta que é preciso detectar os sinais que o mundo emerge, nesse caso, é preciso que durante a formação dos/as professores/as seja dado um enfoque maior para assuntos presentes na nossa sociedade e que refletem nas atitudes dos/as alunos/as, como a violência e indisciplina.

\section{CONCLUSÃO}

Pode-se concluir que a partir dos autores citados no referencial e da análise das professoras pesquisadas foi possível atingir os objetivos traçados no início da pesquisa e encontrar formas para que o curso de Pedagogia possa contribuir com os/as futuros/as professores/as a lidar com a indisciplina nas escolas.

Através da análise foi possível perceber o que os/as professores/as consideram como indisciplina, sendo que as pesquisadas se referem a ela como o descumprimento das regras, mal comportamento e falta de limites por parte da família, salientando que atribuem a culpa da indisciplina à família e não consideraram que ela pode surgir na escola.

Relacionou-se a trajetória da Pedagogia com a indisciplina, ou melhor, disciplina que se tinha na época, já que os educadores eram bem rigorosos e puniam os/as alunos/as que não se comportassem de forma adequada, o que mudou com o decorrer dos anos, mas percebe-se que hoje em dia muitos/as professores/as não sabem como lidar com a indisciplina.

Identificaram-se as maiores dificuldades no início da atuação dos/as professores/as que são referentes ao mau comportamento dos/as alunos/as e em relacionar a teoria e a prática. E através das sugestões das pesquisadas identificou-se possíveis formas de melhor capacitar o/a professor/a durante a formação para enfrentar a indisciplina no âmbito escolar, através de debates, palestras sobre o tema, aproximando a família das escolas e aumentando a carga horária dos estágios obrigatórios. 
Revista do Curso de Graduação de Pedagogia - Unesc

Os/as professores/as possuem um papel fundamental na formação das crianças, precisam compreender que todos são diferentes, que possuem diversas maneiras de ver uma mesma situação, até mesmo as crianças possuem problemas, problemas estes que vem do seio familiar ou até mesmo da organização da escola, e a indisciplina de um/a aluno/a pode ser a forma que ele/a encontra de pedir atenção, pedir ajuda. É preciso um olhar mais atento para compreender de onde vem o problema e buscar maneiras adequadas de intervir, o curso de Pedagogia pode contribuir para que os/as futuros/as professores/as saiam da graduação compreendendo sua função, seguros/as de como lidar com as possíveis situações que poderão encontrar durante sua trajetória na educação e cientes de que precisam rever suas práticas, pois o problema em questão pode estar na sua conduta como professor/a.

Como sugestão para futuras pesquisas abordando a temática indisciplina, consideramos relevante pesquisar sobre as práticas de professores/as que lidam bem com a indisciplina.

\section{REFERÊNCIAS}

ARANHA, Maria Lúcia de Arruda. História da Educação e da Pedagogia: Geral e Brasil. São Paulo, SP: Moderna, 2006.

BRASIL. Estatuto da criança e do adolescente. 3. ed. Brasília: Ministério da Saúde, 2008.

FERREIRA, Antônio Gomes. A educação no Portugal Barroco: Séculos XVI a XVIII. In: STEPHANOU, Maria, BASTOS, Maria Helena Camara. Histórias e memórias da educação no Brasil. Petrópolis, RJ: Vozes, 2004. Vol. 1.

FORTUNA, Tânia Ramos. Indisciplina Escolar: Da compreensão à intervenção. In: XAVIER, Maria. Luisa. M. Disciplina na escola: enfrentamentos e reflexões. Porto Alegre: Mediação, 2002. p. 87-105.

GIL, Antônio Carlos. Como elaborar projetos de pesquisa. $3^{\circ}$ ed. São Paulo: Atlas, 1996.

MICHAELIS: Dicionário prático da língua portuguesa. São Paulo: Editora

Melhoramentos, 2010. 


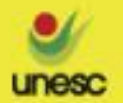

NUNES, Clarice. (Des)encantos da modernidade pedagógica. In: LOPES, Eliane. Marta. Teixeira, FILHO, Luciano. Mendes. Faria. VEIGA, C. G. 500 anos de Educação no Brasil. $2^{\circ}$ ed. Belo Horizonte, BH: Autêntica, 2000. p. $371-395$.

REGO, Teresa Cristina. R. A indisciplina e o processo educativo: uma análise na perspectiva vygtskiana. In: AQUINO, Julio. Groppa. Indisciplina na escola: Alternativas Teóricas e Práticas. São Paulo, SP: Summus, 1996. p. 83-100.

SAVIANI, Dermeval. História das idéias pedagógicas no Brasil. $2^{\circ}$ ed. Campinas, SP: Autores Associados, 2008. 474 p.

SILVA, Carmem Silvia Bissolli da. Curso de Pedagogia no Brasil: história e identidade. Campinas, SP: Autores Associados, 1999. 105 p.

VERONESE, Josiane Rose Petry; VIEIRA, Cleverton Elias. Limites na Educação - Sob a perspectiva da Doutrina da Proteção Integral, do Estatuto da Criança e do Adolescente e da Lei de Diretrizes e Bases da Educação Nacional. Florianópolis, SC: OAB/SC, 2006. 204 p.

VILLELA, Heloisa. O. S. O mestre-escola e a professora. In: LOPES, Eliane. Marta. Teixeira, FILHO, Luciano. Mendes. Faria. VEIGA, C. G. 500 anos de Educação no Brasil. $2^{\circ}$ ed. Belo Horizonte, BH: Autêntica, 2000. p. 95-134

XAVIER, Maria. Luisa. M. Disciplina na escola: enfrentamentos e reflexões. Porto Alegre: Mediação, 2002. 